\title{
RESEARCH
}

Open Access

\section{Effects of Lactobacillus reuteri DSM 17938 in preterm infants: a double-blinded randomized controlled study}

\author{
Xuewei Cui, Yongyan Shi, Siyang Gao, Xindong Xue and Jianhua Fu*
}

\begin{abstract}
Background: Preterm infants have immature gastrointestinal tracts and poor immunity. In this study, the effects of Lactobacillus reuteri DSM 17938 first on early feeding tolerance, growth, and second on infection prevention in preterm infants were evaluated.

Methods: One hundred fourteen formula-fed preterm infants with a gestational age between 30 weeks and 37 weeks, and a birth weight between 1500 and $2000 \mathrm{~g}$ were enrolled; 57 in the intervention and 57 in the control group:the intervention group was given a dose of $1 \times 10^{8}$ colony-forming units ( 5 drops) of L. reuteri DSM 17938 once daily, beginning with the first feeding until discharge. The control group did not receive probiotics. Early feeding tolerance (as time to full enterla feeding and number of reflux), growth, incidences of sepsis, localized infection, NEC, and adverse effects were recorded for both groups.

Results: The number of Daily reflux episodes (times/d) was lower $(2.18 \pm 0.83$ vs. $3.77 \pm 0.66, P<0.01)$ and time to full enteral feedings $(120 \mathrm{~mL} / \mathrm{kg} / \mathrm{d})(9.95 \pm 2.46 \mathrm{~d}$ vs. $13.80 \pm 3.47 \mathrm{~d}, P<0.05)$ was shorter in the intervention group. Average daily weight gain $(14.55 \pm 3.07 \mathrm{~g} / \mathrm{d}$ vs. $10.12 \pm 2.80 \mathrm{~g} / \mathrm{d})$, head circumference increas e $(0.0760 \pm 0.0157 \mathrm{~cm} / \mathrm{d}$ vs. $0.0681 \pm 0.0108 \mathrm{~cm} / \mathrm{d})$, and body length increase $(0.1878 \pm 0.0151 \mathrm{~cm} / \mathrm{d}$ vs. $0.1756 \pm 0.0166 \mathrm{~cm} / \mathrm{d})$ of the intervention group were higher $(P<0.01)$. There were no significant differences in the incidences of sepsis $(4.44 \%$ vs. $8.33 \%$ ), localized infection ( $6.67 \%$ vs. $8.33 \%)$, or NEC (2.22\% vs. $10.42 \%)$ between the 2 groups $(P>0.05)$. The number of daily defecations (times/d) in the intervention group was higher $(3.08 \pm 0.33$ vs. $2.29 \pm 0.20, P<0.01)$ and the length of hospital stay was shorter than that in the control group ( $20.60 \pm 5.36 \mathrm{~d}$ vs. $23.75 \pm 8.57 \mathrm{~d}, P<0.05)$. No adverse effects were noted among the infants receiving $L$. reuteri.
\end{abstract}

Conclusion: L. reuteri may be an useful tool in improving early feeding tolerance in preterm infants, promoting growth, increasing the frequency of defecation, and shortening the length of hospital stay.

Trial registration: ChiCTR, ChiCTR1900025590. Registered 1 February 2019- Retrospectively registered, http://www. chictr.org.cn/listbycreater.aspx.

Keywords: Preterm infant, Lactobacillus reuteri, Feeding tolerance, Growth, Infection prevention

\footnotetext{
* Correspondence: fujh@sj-hospital.org

Department of Neonatology, Shengjing Hospital, China Medical University,

Shenyang, China
}

(C) The Author(s). 2019 Open Access This article is distributed under the terms of the Creative Commons Attribution 4.0 International License (http://creativecommons.org/licenses/by/4.0/), which permits unrestricted use, distribution, and reproduction in any medium, provided you give appropriate credit to the original author(s) and the source, provide a link to the Creative Commons license, and indicate if changes were made. The Creative Commons Public Domain Dedication waiver (http://creativecommons.org/publicdomain/zero/1.0/) applies to the data made available in this article, unless otherwise stated. 


\section{Background}

The survival rate of preterm infants has increased substantially in recent years. Preterm infants, due to their immature development, are characterized by underdeveloped gastrointestinal tracts, delayed colonization of intestinal flora, and low immune function. Therefore, preterm infants are prone to feeding intolerance, infection, and even neonatal necrotizing enterocolitis (NEC), all of which affect growth and quality of life [1].

Probiotics are living microorganisms, which, when administered in adequate amounts, can confer a health benefit to the host [2]. As a microecological preparation, probiotics seem to be useful in nourishing the intestines, adjusting the microbiota, ameliorating immunity and reducing inflammation. In 2017, the World Gastroenterology Organization updated global guidelines about the use of probiotics and prebiotics. A large amount of clinical trials confirmed that probiotics have a beneficial effect on the prevention and treatment of digestive diseases [3]. The clinical application of probiotics in neonates is increasingly widespread for many indications, including the prevention and treatment of feeding intolerance, diarrhea, NEC, neonatal jaundice, and allergic diseases [4].

Lactobacillus reuteri (L. reuteri) DSM 17938 is a progeny strain of $L$. reuteri ATCC 55730, which was originally extracted from the breast milk of Peruvian women living in the Andes. In 2007, 2 plasmids with antibiotic resistance (tetracycline and lincomycin) were removed in order to enhance safety, and the modified strain was stored at The German Center for the Conservation of Microbial Species, also called the DSMZ, and named $L$. reuteri DSM 17938. This strain can live throughout the gastrointestinal tract and colonize in normal human gastric bodies, including the gastric antrum, duodenum, and ileum [5]. In one study, its colonization required continuous supplementation for 7 days, and the highest colonization rate was reached at 21 days; after discontinuing supplementation, the colonization rate decreased significantly at 1 week and was undetectable at 2 months [6]. The role of $L$. reuteri in the effective treatment of infantile colic is clearly illustrated $[7,8]$, and it has been widely used in the prevention and treatment of infantile reflux, functional constipation, and acute gastroenteritis. However, research of the effects of $L$. reuteri on the clinical course in preterm infants is limited.

The aim of the study was to investigate the efficacy of $L$. reuteri in early feeding tolerance, growth, infection prevention, and other aspects of preterm infant development.

\section{Materials and methods}

\section{Patients}

Preterm infants admitted to the First Neonatal Ward of Shengjing Hospital of China Medical University from January 2017 to June 2018 were enrolled for this double-blinded randomized controlled study. Inclusion criteria: formula-fed preterm infants admitted within $12 \mathrm{~h}$ of birth whose gestational age $\geq 30$ and $<37$ weeks; birthweight $\geq 1500 \mathrm{~g}$ and $\leq 2000 \mathrm{~g}$ with vital sign and hemodynamic parameters stable. Exclusion criteria: congenital diseases, expected hospitalization less than 2 weeks and maternal or neonatal antibiotics or other probiotics before admission.

The study was approved by the Medical Ethics Committee of Shengjing Hospital of China Medical University. Informed consent was obtained from the infants' parents. Randomization was conducted according to a random computer-determined allocation order considering gestational age.

\section{Study design}

After admission, routine treatment and nursing support were provided for all infants enrolled according to their conditions. Formula milk feeding (provided by the hospital, $335 \mathrm{~kJ} / 100 \mathrm{~mL}$, Abbott Laboratories, USA) was given to the preterm infants after stabilization, started with $20 \mathrm{~mL} / \mathrm{kg} / \mathrm{d}$ and was defined as full enteral feeding when $120 \mathrm{~mL} / \mathrm{kg} / \mathrm{d}$ were reached. Increment were $10-20 \mathrm{~mL} / \mathrm{kg} / \mathrm{d}$ depending on the gestational age of the infant. The amount of feeding was advanced if tolerated with $10-20 \mathrm{~mL} / \mathrm{kg} / \mathrm{d}$. This feeding policy was not altered during the study period. Parenteral nutrition was supplemented for undernutrition, as defined by the "Guidelines for Clinical Application of Neonatal Nutrition Support in China" [9]. L. reuteri DSM 17938 (Biogaia $\mathrm{AB}$, Stockholm, Sweden) was administered to the preterm infants in the intervention group at a dose of $1 \times 10^{8}$ colony-forming units (5 drops) once daily, beginning with the first feeding until discharge from the hospital. For infants who were fed orally, 5 drops were instilled to the posterior oropharynx of the infants after suctioning oral secretions. For infants without oral feeds, 5 drops were administered through a gastric tube followed by a flush of $0.5 \mathrm{~mL}$ of sterile water. The minimum duration of the intervention was 7 days. No probiotics were administered to the control group. If enteral feeding was stopped due to feeding intolerance such as increased abdominal girth, emesis, gastric residual of $25 \%$ of the previous feed volume or NEC during hospitalization, $L$. reuteri was stopped and resumed after feeding resumed. Blinding was possible because the nurses who administered $L$. reuteri to the infants were not involved in the daily care and the attending neonatal team was unaware of the randomization assignments.

\section{Primary and secondary outcomes}

Primary outcomes of this study were feeding tolerance and growth in preterm infants. Secondary outcome was infection prevention. To assess feeding tolerance, the time to full enteral feedings (TFF) and number of reflux episodes were recorded. To assess growth indicators, we 
measured the growth of body weight, body length, and head circumference, calculating the difference of these parameters at the end toward the beginning of study period, then we divided them as daily increase. To assess infection prevention, incidences of nosocomial infection and NEC were recorded. Adverse effects, including culture-proven sepsis, flatulence and diarrhoea were also recorded.

\section{Definitions and diagnostic criteria}

Reflux was defined as the passage of refluxed gastric contents into the oral pharynx [10]. Nosocomial infection was defined as an infection occurring after $48 \mathrm{~h}$ of hospitalization, including infections that occurred during hospitalization and infections that occurred after discharge from pathogens to which infants were exposed in the hospital [11]. NEC was defined as acute necrotizing intestinal disease with abdominal distension, vomiting, and hematochezia as the main symptoms. NEC may be caused by various factors in the perinatal period; it should be diagnosed according to clinical manifestations and abdominal X-rays and should be categorized by modified Bell's classification [12].

\section{Statistical analysis}

SPSS Statistics version 24 statistical software was used for statistical analysis. The measurement data are presented as means \pm standard deviations. The $\mathrm{t}$-test was used for comparisons between groups. Categorical data were compared by the $x^{2}$ test. A $p$-value of less than 0.05 was considered statistically significant. This study was registered at the website http://www.chictr.org.cn/listbycreater.aspx under the number ChiCTR1900025590.

\section{Results}

\section{Patient description}

A total of 114 cases were eventually enrolled and randomly allocated in the study. 57 patients received $L$. reuteri and 57 neonates were included in the control group. In all, 21 (18\%) patients were excluded because of major congenital malformations and the using of other probiotics (12 [21.1\%] in the intervention group and 9 [15.8\%] in the control group). Finally, 45 cases could be analyzed in the intervention group and 48 cases in the control group (Fig. 1).

The characteristics of the preterm infants at study inclusion are shown in Table 1. There were no significant differences in gender, gestational age, birth weight, or Apgar score between the 2 groups.

\section{Primary and secondary outcomes}

The study outcomes observed in the two study groups are shown and compared in Table 2.

\section{Feeding tolerance}

The number of daily reflux episodes (times/d) in the intervention group was significantly lower than that in the control group ( $2.18 \pm 0.83$ vs. $3.77 \pm 0.66, P<0.01)$. TFF in the intervention group was significantly shorter than that in the control group $(9.95 \pm 2.46 \mathrm{~d}$ vs. $13.80 \pm 3.47 \mathrm{~d}, P<0.05)$.

\section{Growth}

The average daily weight gain $(14.55 \pm 3.07 \mathrm{~g} / \mathrm{d}$ vs. $10.12 \pm 2.80 \mathrm{~g} / \mathrm{d}$ ), daily head circumference growth $(0.0760 \pm 0.0157 \mathrm{~cm} / \mathrm{d}$ vs. $0.0681 \pm 0.0108 \mathrm{~cm} / \mathrm{d})$, and body length increase $(0.1878 \pm 0.0151 \mathrm{~cm} / \mathrm{d}$ vs. $0.1756 \pm$ $0.0166 \mathrm{~cm} / \mathrm{d}$ ) of the preterm infants in the intervention group were significantly higher than those of the control group $(P<0.01)$.

\section{Infection}

Nosocomial infection could be divided into sepsis and localized infection. In this study, there were 2 cases of sepsis and 3 cases of localized infection ( 2 cases of neonatal pneumonia, 1 case of urinary tract infection) in the intervention group while 4 cases of sepsis and 4 cases of localized infection (3 cases of neonatal pneumonia, 1 case of urinary tract infection) in the control group. There was no significant difference in the incidences of sepsis $(4.44 \%$ vs. $8.33 \%)$, localized infection $(6.67 \%$ vs. $8.33 \%)$ or NEC $(2.22 \%$ vs. $10.42 \%)$ between the 2 groups $(P>0.05)$.

\section{Other indicators}

The number of daily defecations in the intervention group was $3.08 \pm 0.33$, which was $2.29 \pm 0.20$ in the control group. The length of hospital stay in the intervention group was shorter than that in the control group $(20.60 \pm 5.36 \mathrm{~d}$ vs. $23.75 \pm 8.57 \mathrm{~d}, P<0.05)$. The preterm infants in the intervention group had no adverse effects while receiving $L$. reuteri.

\section{Discussion}

Preterm infants have poor sucking and swallowing abilities, immature digestive systems, insufficient gastrointestinal motility, and low gastrointestinal mucosal barrier function, and they are prone to feeding intolerance such as regurgitation, vomiting, abdominal distension, and gastric retention during feeding [13]. Studies have shown that probiotics could stimulate the secretion of gastrin and motilin, promote gastrointestinal motility, reduce the incidence of feeding intolerance, and shorten the time to achieve total enteral nutrition [14]. Reflux refers to the reverse movement of gastric contents, usually referred to gastroesophageal reflux (GOR). GOR is a prominent condition among preterm infants. Symptoms such as apnoea, bradycardia, vomiting, poor weight gain and irritability have been attributable to GOR, which is called 


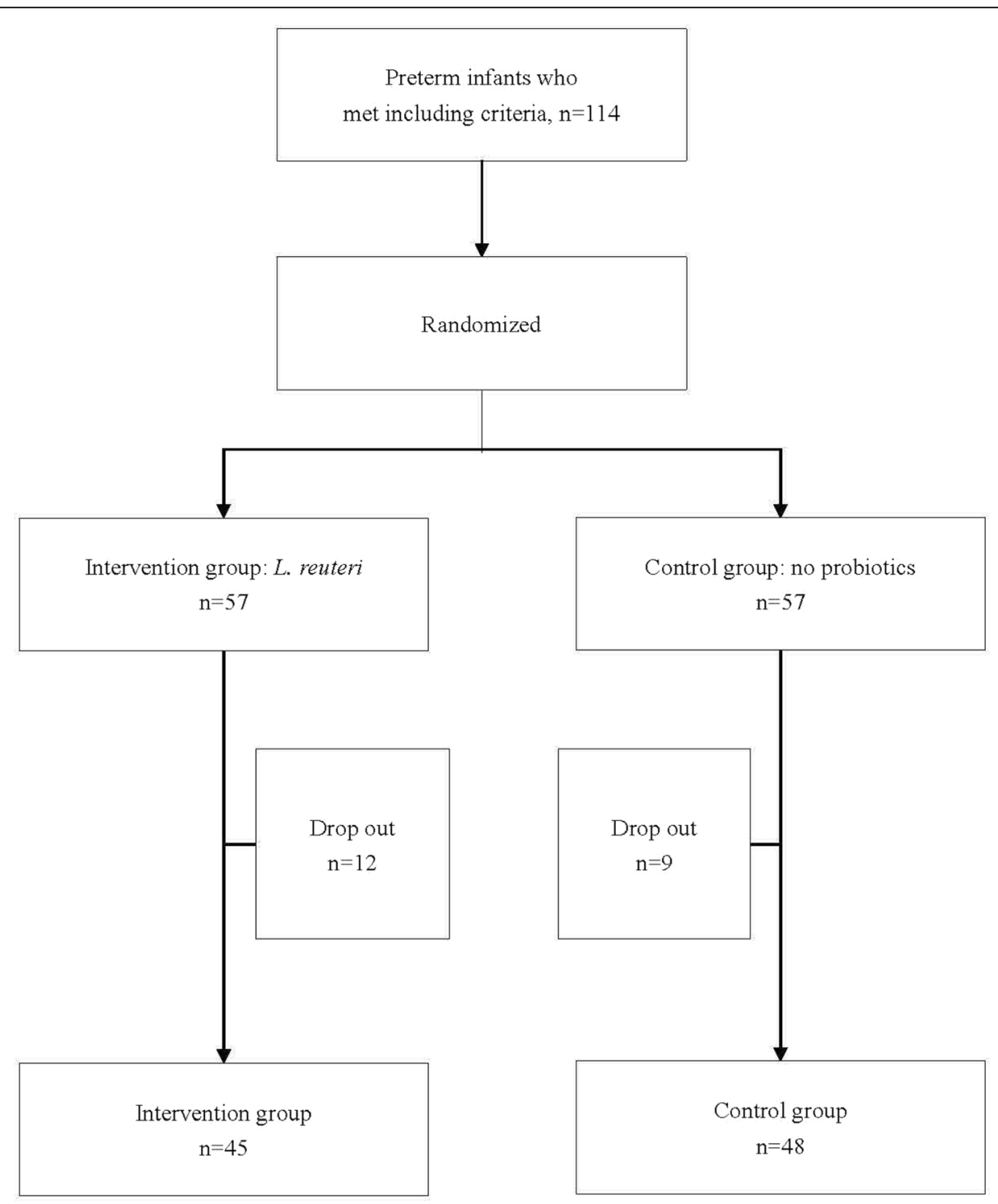

Fig. 1 Study flow chart

gastroesophageal reflux disease (GORD), when symptoms are severe [15]. Experimental data showed that L. reuteri can promote gastric motility, accelerate gastric emptying, promote colonic peristalsis, and reduce the incidence of dyspepsia and reflux $[16,17]$. Indrio et al. [18] conducted

Table 1 Comparison of the Characteristics Between the 2 Groups of Preterm Infants

\begin{tabular}{llll}
\hline Group & Intervention group & Control group & $P$ \\
\hline$n$ & 45 & 48 & \\
Gender $(M / F)$ & $25 / 20$ & $20 / 28$ & \\
Gestational age $\left(\bar{x}_{(\mathrm{sd}), \text { weeks }}\right)$ & $32.85(1.39)$ & $32.56(1.41)$ & 0.3206 \\
5 min Apgar score $\left(\bar{x}_{(\mathrm{sdd})}\right)$ & $9.29(0.84)$ & $9.29(0.82)$ & 0.9872 \\
Birth weight $\left(\bar{x}_{(\mathrm{sd}), \mathrm{g})}\right.$ & $1682(109.03)$ & $1714(127.11)$ & 0.1984
\end{tabular}

$\overline{\bar{x}}(\mathrm{sd})$, means (standard deviation) a randomized, double-blind, controlled study of 30 preterm infants: 10 preterm infants were exclusively breastfed and the remaining 20 were fed formula; the formula-fed infants were randomly assigned to receive $L$. reuteri or a placebo for 30 days. The results showed that the number of reflux episodes in the $L$. reuteri group was significantly lower than that in the placebo group $(P<0.01)$. Moreover, the incidence of reflux episodes in the supplemented group resulted similar to that of the breastfed group. It demonstrated that oral supplementation with $L$. reuteri improved feeding tolerance in preterm infants. This is consistent with our findings. Our study demonstrated that L. reuteri was able to reduce severity and number of reflux episodes (GORD incidence was $8.88 \%$ in the intervention vs. $12.5 \%$ in the control group). We may speculate that this lead to a shorter TFF, thus improving the rapidity of 
Table 2 Comparison of Feeding Tolerance, Growth, and Infection incidence Between the 2 Groups

\begin{tabular}{|c|c|c|c|c|c|}
\hline & Intervention group & Control group & $t$ & $x^{2}$ & $P$ \\
\hline \multicolumn{6}{|l|}{ Feeding tolerance } \\
\hline Reflux (times/d) & $2.18 \pm 0.83$ & $3.77 \pm 0.66$ & -10.250 & & 0.000 \\
\hline TFF (d) & $9.95 \pm 2.46$ & $13.80 \pm 3.47$ & -2.874 & & 0.015 \\
\hline \multicolumn{6}{|l|}{ Growth } \\
\hline Weight gain (g/d) & $14.55 \pm 3.07$ & $10.12 \pm 2.80$ & 7.269 & & 0.000 \\
\hline $\mathrm{HC}$ increase $(\mathrm{cm} / \mathrm{d})$ & $0.0760 \pm 0.0157$ & $0.0681 \pm 0.0108$ & 2.794 & & 0.007 \\
\hline Body length increase $(\mathrm{cm} / \mathrm{d})$ & $0.1878 \pm 0.0151$ & $0.1756 \pm 0.0166$ & 3.687 & & 0.000 \\
\hline \multicolumn{6}{|l|}{ Infection incidence } \\
\hline Sepsis & $4.44 \%$ & $8.33 \%$ & & 0.582 & 0.446 \\
\hline Localized infection & $6.67 \%$ & $8.33 \%$ & & 0.093 & 0.761 \\
\hline NEC & $2.22 \%$ & $10.42 \%$ & & 2.584 & 0.108 \\
\hline \multicolumn{6}{|l|}{ Other indicators } \\
\hline Defecation (times/d) & $3.08 \pm 0.33$ & $2.29 \pm 0.20$ & 13.891 & & 0.006 \\
\hline Hospital stay (d) & $20.60 \pm 5.36$ & $23.75 \pm 8.57$ & -2.139 & & 0.036 \\
\hline
\end{tabular}

HC head circumference, NEC neonatal necrotizing enterocolitis, TFF time to full enteral feedings

the growth of formula-fed preterm infants. Our study also found that oral administration of $L$. reuteri may increase the daily defecation frequency of formula-fed preterm infants and shorten their hospital stays. Our study showed that no adverse effects occurred while formula-fed preterm infants were receiving L. reuteri, which was consistent with the results of Oncel et al. [19].

In the neonatal period, infections are common and are a major risk factor for neonatal death, especially septicemia, which has an insidious onset and rapid progression [20]. The digestive tract of preterm infants is hypoplasic, bacterial flora is less diverse, and colonization is delayed compared to full-term infants. Most digestive bacteria, including Klebsiella, Enterobacter, and Clostridium, are potentially pathogenic and can trigger digestive tract injury. Digestive tract injury combined with the deficiency of the innate immune system increases the probability that pathogens will spread throughout the entire body and cause a systemic infection [21]. Probiotics influence the functions of various immune cells, such as lymphocytes and dendritic cells, by direct or indirect regulation and they play a role in immune regulation and control of inflammation progression. L. reuteri DSM 17938 can ferment in vivo to produce acetic acid and reuterin. Acetic acid can lower the $\mathrm{pH}$ in vivo and it has a strong antibacterial effect on many pathogens; reuterin can cause oxidative stress in pathogens and effectively resist bacteria [22, 23]. Valeur [5] reported that $L$. reuteri activated CD4+ Thcells and coordinated other immune cells to regulate the immune response. Preidis et al. [24] showed that $L$. reuteri could significantly induce the production of immunoglobulin A, inhibit the adhesion of bacteria and viruses to epithelial cells, and neutralize toxins. A randomized controlled trial showed that $L$. reuteri significantly reduced the incidence of diarrhea and respiratory infections in preschoolers, as well as shortened the course of disease [25]. Oncel et al. [26] reported that L. reuteri could significantly reduce the incidence of septicemia in extremely low birthweight (ELBW) infants with a gestational age of less than 32 weeks $(6.5 \%$ vs. $12.5 \%$, $P=0.041)$. On the contrary, in our study, there were no statistical differences in the incidence of sepsis ( $4.44 \%$ vs. $8.33 \%, P>0.05)$ or localized infection $(6.67 \%$ vs. $8.33 \%, P>0.05)$ between the two groups. These two different results may be related to different sub-population, gestational age, birth weight or feeding patterns. Whether $L$. reuteri can prevent infection should be verified with larger sample sizes in future research.

The main pathogenesis of NEC include immature intestinal development, imperfect intestinal flora, formula feeding, and circulation disorders. The establishment of the microecological environment in the gastrointestinal tract is significant for maintaining the stability of the body environment and inhibiting intestinal inflammation. Breastfeeding is currently the only recognized protective factor against NEC. Research has confirmed that probiotics could effectively prevent and reduce the incidence of NEC in preterm infants $[27,28]$. L. reuteri can improve the intestinal microecological environment, maintain the integrity of the gastrointestinal mucosal barrier, directly or indirectly regulate a variety of immune cell functions, and control the progression of intestinal inflammation [29]. Liu et al. [30, 31] found that $L$. reuteri could significantly down-regulate the level of tumor necrosis factor alpha by regulating TLR2, TLR4, and NF-KB signaling pathways in the intestine and reduce the incidence and severity of experimental 
NEC in rats. Hunter et al. [32] retrospectively analyzed 311 ELBW infants (79 cases with oral $L$. reuteri administration) and found that the incidence of NEC was significantly reduced in neonates receiving $L$. reuteri $(15.1 \%$ vs. $2.5 \%, P=$ 0.0475). Our study showed that the incidence of NEC in the intervention group was $2.22 \%$ ( 1 case, stage IIA), while the incidence of NEC in the control group was $10.42 \%$ ( 5 cases in total: 3 cases in stage IIB, 2 cases in stage IIIA), which showed no statistically significant difference between the 2 groups $(P>0.05)$. More research is needed to confirm if oral administration of $L$. reuteri can reduce the incidence and severity of NEC in formula-fed preterm infants.

\section{Conclusion}

In summary, L. reuteri DSM17938, as a safe microecological preparation, can reduce daily reflux, shorten the TFF; improve early feeding tolerance; accelerate increases in body weight, body length, and head circumference; promote growth; increase the frequency of defecation; and shorten the length of hospital stay in formula-fed preterm infants. Large sample sizes and multicenter studies are needed to confirm if oral administration of $L$. reuteri can reduce the incidences of nosocomial infection and NEC.

\section{Abbreviations}

HC: Head circumference; L. reuteri: Lactobacillus reuteri; NEC: Necrotizing enterocolitis; TFF: Time to full enteral feedings

\section{Acknowledgements}

We are grateful to Li Yunyang, M.S.M, Shenyang Yike biotechnology co. LTD, and Chen Jing, Sc.D., Shenyang Agriculture University, for their help with the statistical analysis.

\section{Authors' contributions}

CX and FJ: designed research; CX, GS and SY: conducted research and collected data; CX: wrote the manuscript; XX and SY: directed the writing of the manuscript; FJ: had primary responsibility for final content. All authors designed, supervised, and analyzed the study and assisted with the preparation of the manuscript. All authors read and approved the final manuscript.

\section{Funding}

None.

\section{Availability of data and materials}

The datasets generated and analysed during the current study are available in the Harvard Dataverse repository, https://doi.org/10.7910/DVN/XAEKOF

\section{Ethics approval and consent to participate}

The study was approved by the Medical Ethics Committee of Shengjing Hospital of China Medical University.

\section{Consent for publication}

Informed consent was obtained from the infants' parents.

\section{Competing interests}

The authors declare that they have no competing interests.
Received: 29 March 2019 Accepted: 11 September 2019

Published online: 09 November 2019

\section{References}

1. Tudehope D, Fewtrell M, Kashyap S, Udaeta E. Nutritional needs of the micropreterm infant. J Pediatr. 2013;162(3):S72-80. https://doi.org/10.1016/j. jpeds.2012.11.056

2. Hill C, Guarner F, Reid G, Gibson GR, Merenstein DJ, Pot B, et al. Expert consensus document: the international scientific Association for Probiotics and Prebiotics consensus statement on the scope and appropriate use of the term probiotic. Nat Rev Gastroenterol Hepatol. 2014;11(8):506-14. https://doi.org/10.1038/nrgastro.2014.66.

3. Guarner F, Khan AG, Garisch J, Eliakim R, Gangl A, Thomson A, et al. World gastroenterology organisation global guidelines: probiotics and prebiotics october 2011. J Clin Gastroenterol. 2012:46(6):468-81. https://doi.org/10. 1097/MCG.0b013e3182549092

4. Indrio F, Riezzo G, Raimondi F, Bisceglia M, Cavallo L, Francavilla R. Effects of probiotic and prebiotic on gastrointestinal motility in newborns. J Physiol Pharmacol. 2009;60(Suppl 6):27-31.

5. Valeur N, Engel P, Carbajal N, Connolly E, Ladefoged K. Colonization and immunomodulation by lactobacillus reuteri ATCC 55730 in the human gastrointestinal tract. Appl Environ Microbiol. 2004;70(2):1176-81. https://doi. org/10.1128/AEM.70.2.1176-1181.2004

6. Wolf B, Garleb K, Ataya D, Casas I. Safety and tolerance of lactobacillus reuteri in healthy adult male subjects. Microb Ecol Health Dis. 1995;8(2):4150. https://doi.org/10.3109/08910609509141381.

7. Cameron D, Hock QS, Kadim M, Mohan N, Ryoo E, Sandhu B, et al. Probiotics for gastrointestinal disorders: proposed recommendations for children of the Asia-Pacific region. World J Gastroenterol. 2017;23(45):795264. https://doi.org/10.3748/wjg.v23.i45.7952.

8. Hojsak I, Fabiano V, Pop TL, Goulet O, Zuccotti GV, Çokuğraş FC, et al. Guidance on the use of probiotics in clinical practice in children with selected clinical conditions and in specific vulnerable groups. Acta Paediatr. 2018;107(6):927-37. https://doi.org/10.1111/apa.14270.

9. Cai W, Tang Q, Wang Y, Fen Y, Wu J, Qian L. Guidelines for clinical application of neonatal nutrition support in China. J Clin Pediatr. 2013;31(12):1177-82.

10. Rudolph CD, Mazur LJ, Liptak GS, Baker RD, Boyle JT, Colletti RB, et al. Guidelines for evaluation and treatment of gastroesophageal reflux in infants and children: recommendations of the north American Society for Pediatric Gastroenterology and Nutrition. J Pediatr Gastroenterol Nutr. 2001; 32:S1-S31. https://doi.org/10.1097/00005176-200100002-00001.

11. Stoll BJ. Infections of the neonatal infant. In: Behrman R, Kliegman R, $H B$ J, editors. Nelson textbook of pediatrics. 17th ed. Philadelphia: WB Saunders; 2004.

12. Walsh MC, Kliegman RM, Fanaroff AA. Necrotizing enterocolitis: a practitioner's perspective. Pediatr Rev. 1988;9(7):219-26. https://doi.org/10.1542/pir.9-7-219.

13. Vandenplas Y, Gutierrez-Castrellon P, Velasco-Benitez C, Palacios J, Jaen D, Ribeiro $\mathrm{H}$, et al. Practical algorithms for managing common gastrointestinal symptoms in infants. Nutrition. 2013;29(1):184-94. https://doi.org/10.1016/j.nut.2012.08.008.

14. Olsen R, Greisen G, Schrøder M, Brok J. Prophylactic probiotics for preterm infants: a systematic review and meta-analysis of observational studies. Neonatology. 2016;109(2):105-12. https://doi.org/10.1159/000441274.

15. Dermyshi E, Mackie C, Kigozi P, Schoonakker B, Dorling J. Antacid therapy for gastroesophageal reflux in preterm infants: a systematic review. BMJ Paediatr Open. 2018;2(1):e000287. https://doi.org/10.1136/bmjpo-2018-000287.

16. Garofoli F, Civardi E, Indrio F, Mazzucchelli I, Angelini M, Tinelli C, et al. The early administration of lactobacillus reuteri DSM 17938 controls regurgitation episodes in full-term breastfed infants. Int J Food Sci Nutr. 2014;65(5):646-8. https://doi.org/10.3109/096374866.2014.898251.

17. Wu R, Pasyk M, Wang B, Forsythe P, Bienenstock J, Mao YK, et al. Spatiotemporal maps reveal regional differences in the effects on gut motility for lactobacillus reuteri and rhamnosus strains. Neurogastroenterol Motil. 2013;25(3):e205-e14. https://doi.org/10.1111/nmo.12072.

18. Indrio F, Riezzo G, Raimondi F, Bisceglia M, Cavallo L, Francavilla R. The effects of probiotics on feeding tolerance, bowel habits, and gastrointestinal motility in preterm newborns. J Pediatr. 2008;152(6):801-6. https://doi.org/10.1016/j. jpeds.2007.11.005.

19. Oncel MY, Arayici S, Sari FN, Simsek GK, Yurttutan S, Erdeve O, et al. Comparison of lactobacillus reuteri and nystatin prophylaxis on Candida colonization and infection in very low birth weight infants. J Matern-Fetal Neonat Med. 2015; 28(15):1790-4. https://doi.org/10.3109/14767058.2014.968842. 
20. Khair K, Rahman M, Sultana T, Roy C, Rahman M, Ahmed A. Early diagnosis of neonatal septicemia by hematologic scoring system, C-reactive protein and serum haptoglobin. Mymensingh Med J. 2012;21(1):85-92.

21. Ouwehand AC. What role for probiotics in Necrotising enterocolitis. Arch Pediatr. 2014;2(3):e14912. https://doi.org/10.5812/pedinfect.14912.

22. De Weirdt R, Crabbé A, Roos S, Vollenweider S, Lacroix C, van Pijkeren JP, et al. Glycerol supplementation enhances $L$. reuteri's protective effect against S. typhimurium colonization in a 3-D model of colonic epithelium. PLoS One. 2012;7(5):e37116. https://doi.org/10.1371/journal.pone.0037116.

23. Schaefer $L$, Auchtung TA, Hermans KE, Whitehead D, Borhan B, Britton RA. The antimicrobial compound reuterin (3-hydroxypropionaldehyde) induces oxidative stress via interaction with thiol groups. Microbiology. 2010;156(6): 1589-99. https://doi.org/10.1099/mic.0.035642-0.

24. Preidis GA, Saulnier DM, Blutt SE, Mistretta T-A, Riehle KP, Major AM, et al. Probiotics stimulate enterocyte migration and microbial diversity in the neonatal mouse intestine. FASEB J. 2012;26(5):1960-9. https://doi.org/10. 1096/fj.10-177980

25. Gutierrez-Castrellon P, Lopez-Velazquez G, Diaz-Garcia L, Jimenez-Gutierrez C, Mancilla-Ramirez J, Estevez-Jimenez J, et al. Diarrhea in preschool children and lactobacillus reuteri: a randomized controlled trial. Pediatrics. 2014;133(4):904-9. https://doi.org/10.1542/peds.2013-0652.

26. Oncel MY, Sari FN, Arayici S, Guzoglu N, Erdeve O, Uras N, et al. Lactobacillus reuteri for the prevention of necrotising enterocolitis in very low birthweight infants: a randomised controlled trial. Arch Dis Child-Fetal Matern Ed. 2014; 99(2):F110-F5. https://doi.org/10.1136/archdischild-2013-304745.

27. Deshpande G, Rao S, Patole S, Bulsara M. Updated meta-analysis of probiotics for preventing necrotizing enterocolitis in preterm neonates. Pediatrics. 2010;125(5):2009-1301. https://doi.org/10.1542/peds.2009-1301.

28. Dylag K, Hubalewska-Mazgaj M, Surmiak M, Szmyd J, Brzozowski T. Probiotics in the mechanism of protection against gut inflammation and therapy of gastrointestinal disorders. Curr Pharm Des. 2014;20(7):1149-55. https://doi.org/10.2174/13816128113199990422.

29. Lau CS, Chamberlain RS. Probiotic administration can prevent necrotizing enterocolitis in preterm infants: a meta-analysis. J Pediatr Surg. 2015;50(8): 1405-12. https://doi.org/10.1016/j.jpedsurg.2015.05.008.

30. Liu Y, Fatheree NY, Mangalat N, Rhoads JM. Lactobacillus reuteri strains reduce incidence and severity of experimental necrotizing enterocolitis via modulation of TLR4 and NF-KB signaling in the intestine. Am J Physiol Gastrointest Liver Physiol. 2012;302(6):G608-G17. https://doi.org/10.1152/ajpgi.00266.2011.

31. Hoang TK, He B, Wang T, Tran DQ, Rhoads JM, Liu Y. Protective effect of lactobacillus reuteri DSM 17938 against experimental necrotizing enterocolitis is mediated by toll-like receptor 2. Am J Physiol Gastrointest Liver Physiol. 2018;315(2):231-40. https://doi.org/10.1152/ajpgi.00084.2017.

32. Hunter C, Dimaguila MAV, Gal P, Wimmer JE, Ransom JL, Carlos RQ, et al. Effect of routine probiotic, lactobacillus reuteri DSM 17938, use on rates of necrotizing enterocolitis in neonates with birthweight< 1000 grams: a sequential analysis. BMC Pediatr. 2012;12(1):142. https://doi.org/10.1186/1471-2431-12-142.

\section{Publisher's Note}

Springer Nature remains neutral with regard to jurisdictional claims in published maps and institutional affiliations.

Ready to submit your research? Choose BMC and benefit from:

- fast, convenient online submission

- thorough peer review by experienced researchers in your field

- rapid publication on acceptance

- support for research data, including large and complex data types

- gold Open Access which fosters wider collaboration and increased citations

- maximum visibility for your research: over $100 \mathrm{M}$ website views per year

At $\mathrm{BMC}$, research is always in progress.

Learn more biomedcentral.com/submissions 